\title{
p16-negative warty carcinoma of the uterine cervix with superficial invasion to the endometrium: A case report focusing on diagnostic pitfalls
}

\author{
Hyun-Jung Kim*1, Chul Min Lee ${ }^{2}$ \\ ${ }^{1}$ Department of Pathology, Inje Univ. Sanggye Paik Hospital, Seoul, Republic of Korea \\ ${ }^{2}$ Department of Gynecology, Inje Univ. Sanggye Paik Hospital, Seoul, Republic of Korea
}

Received: May 24, 2017

DOI: $10.5430 /$ crcp.v4n3p12

\author{
Accepted: July 16, 2017 \\ Online Published: July 24, 2017 \\ URL: https://doi.org/10.5430/crcp.v4n3p12
}

\begin{abstract}
Warty carcinoma of the uterine cervix is a very rare and specific variant of invasive squamous cell carcinoma, usually described as a hybrid of the features of both condyloma acuminatum and invasive squamous cell carcinoma. The diagnostic pitfalls of this lesion are: 1) the bland appearance of cytomorphology, 2) distinct koilocytotic atypia, and 3) p16 negativity. A case of warty carcinoma with a fungating mass on the uterine cervix of a 75-year-old woman is presented. The original diagnosis by punch biopsy was atypical squamous cells, undetermined for malignancy, adjunct with p16 negativity. The subsequent radical hysterectomy showed a protruding mass $(5.7 \mathrm{~cm}$ in horizontal dimension) of the uterine cervix. Light microscopy revealed a protruding mass composed of exophytic papillae and inverted nests along the endocervical glands. There were multiple micro-invasive foci $(<1 \mathrm{~mm})$ of tongue like projections at the nest base and slight involvement of the upper vagina and endometrial surface. The p16 immunohistochemical staining yielded negative results. The results of the HPV DNA chip test from paraffin-embedded tissue were 6 (low risk, +++) and 42 (low risk, +). The Ki-67 proliferation index was approximately $20 \%$. The invasive foci and patient's age were the determining differential factors for malignancy rather than benign condylomatous lesion.
\end{abstract}

Key Words: Warty carcinoma, Uterine cervix, p16 negative, HPV, Condyloma

\section{INTRODUCTION}

Warty carcinoma was originally described as a lesion of the vulva or anus but has recently been classified as a variant of invasive squamous cell carcinoma (SCC). ${ }^{[1]}$ This lesion is histologically similar to condyloma acuminatum (i.e. diffuse koilocytotic atypia, no unequivocal atypia). In addition, these tumors seem less aggressive than classic squamous cell carcinoma, with low-risk human papilloma virus (HPV) types having been identified. ${ }^{[2]}$ The expression of p16 and HPV-status have been well- established as important di- agnostic markers for high-grade squamous intraepithelial lesions (HSIL) and SCC in the female genital tract. ${ }^{[3]} \mathrm{We}$ present the case of a 75-year-old woman who presented with a fungating cervical mass and no associated p16 expression or definite histomorphology of HSIL.

\section{CASE PRESEnTAtion}

\subsection{Clinical summary}

A 75-year-old woman was transferred from a local clinic to our institution owing to the diagnoses of a squamous cell

${ }^{*}$ Correspondence: Hyun-Jung Kim; Email: hjkim@paik.ac.kr; Address: Department of Pathology, Inje University, Sanggye Paik Hospital, 1342, Dongilro, Nowon-gu, Seoul 01757, Republic of Korea. 
carcinoma on cytology (pap smear) and an uterine cervical mass, suspected for malignancy. Several differential grade of abnormal pap smear-results (ASCUS, HSIL, and finally squamous cell carcinoma) were reported to her within 4 years and tissue biopsies showed chronic cervicitis, CIN I and CIN I with HPV infection through out-hospital chart review. The HPV test yielded positive results for type 6 (low risk). She complained a slight abdominal dull pain (pain scale 2 out of 10) without vaginal bleeding. Pelvic magnetic resonance imaging (MRI) showed a high signal intensity (SI) mass of the uterine cervix on T2W1, suspicious for cervical carcinoma (FIGO stage IB1) (see Figure 1). On punch biopsy, a definite diagnosis had not been obtained, and subsequently a radical hysterectomy with pelvic lymphadenectomy had been performed. The diagnosis of the punch biopsy was atypical squamous cells (not definite for malignancy).

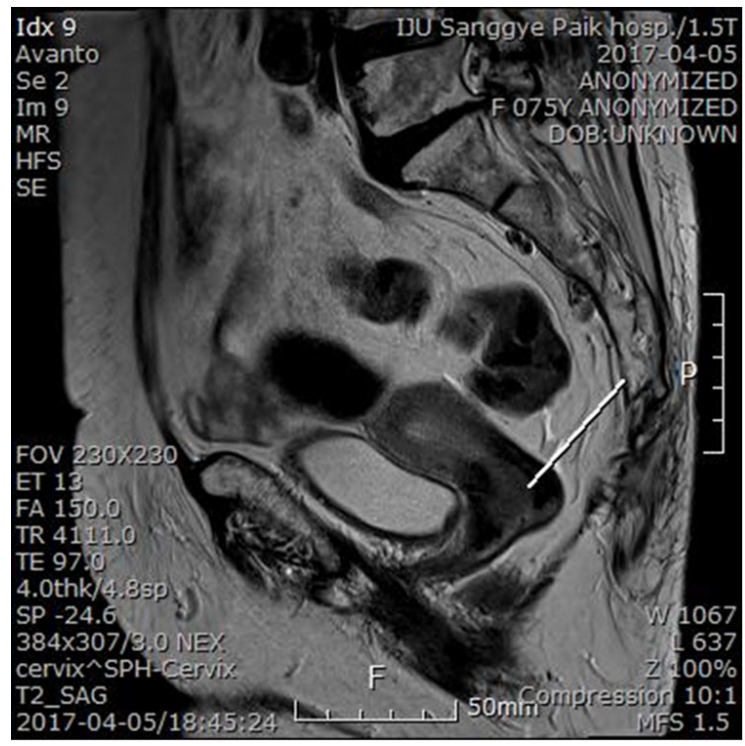

Figure 1. Pelvic magnetic resonance image showing a high SI mass in the uterine cervix, suspicious for cervical carcinoma

\subsection{Pathologic findings}

The gross specimen showed an ill-defined protruding mass $(5.7 \mathrm{~cm} \times 2.7 \mathrm{~cm} \times 2.0 \mathrm{~cm})$ of the uterine cervix, which superficially extended to the lower portion of the endometrium and upper vagina (see Figure 2). The tumor's external surface was thick-whitish and relatively smooth. The cut surface of the mass was gray-whitish and granular without necrosis or hemorrhage.

Light microscopy showed basically endophytic growth, with condylomatous fronds on the top portion (see Figure 3A). Both aspects were composed of thickened squamous epithelium with distinct koilocytotic atypia (perinuclear halo, irregular nuclear membrane, hyperchromatic nuclei, and abundant Published by Sciedu Press cytoplasm, see Figure 3B). There were multiple foci with tongue-like projections below the basement membrane (see Figure 3C). The endometrium was involved with condylomatous squamous nests along endometrial glands (see Figure 3D). The Ki-67 labeling index was approximately $20 \%$ in the hot spot (see Figure 3E). Immunohistochemical staining yielded negative results for p16 expression (see Figure 3F). The results of the HPV DNA chip test extracted from paraffin embedded tissue were 6 (low risk, +++ ) and 42 (low risk, $+)$. She was well without evidence of disease three months post-operatively.

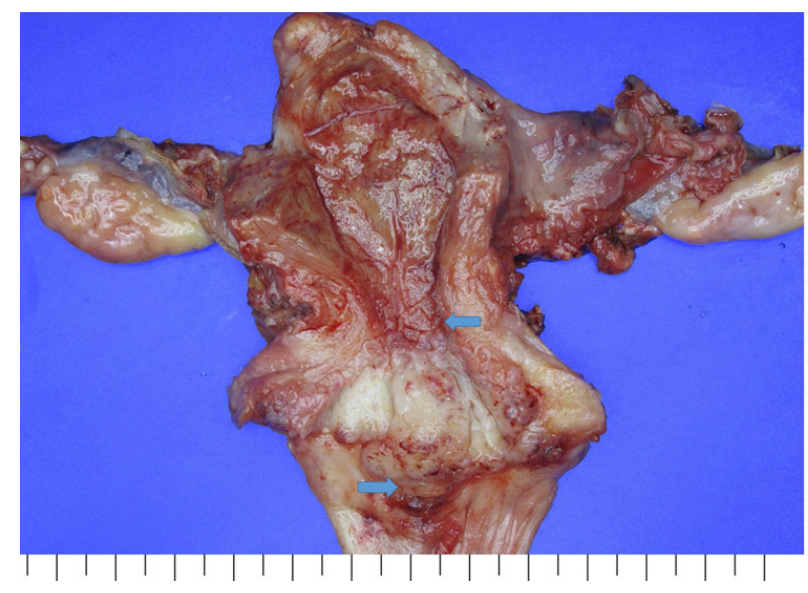

Figure 2. The gross findings of a radical hysterectomy specimen revealed an ill-defined and protruding mass $(5.7 \mathrm{~cm} \times 2.7 \mathrm{~cm} \times 2 \mathrm{~cm})$ of the uterine cervix, which superficially extended to lower portion of the endometrium, and the upper vagina (arrows)

\section{Discussion}

Malignant warty lesions of the uterine cervix are very rare and originally described as a vulvar and anal lesion. This condition has historically been described as "SCC following condyloma acuminatum"[4,5] and "SCC associated with Buschke-Löewenstein giant condyloma."[6] The malignant transformation from condyloma is supported by 1) the presence of koilocytes in the superficial and intermediated levels of the epithelium, 2) association with low-risk HPV subtypes, 3) relatively low level of $\mathrm{Ki}-67$ proliferation index, and 4) p16 negativity. The presented case showed all four compatiable features, too.

The koilocytotic atypia is a pivotal differential factor to distinguish from other papillary forms of SCCs, such as verrucous carcinoma and papillary SCC. Verrucous carcinoma has characteristic bulbous rete pegs deep in the stroma and a complete absence of koilocytes. ${ }^{[7]}$ Papillary SCC has papillary fronds lined by epithelial cells simulating transitional cells without koilocytes. ${ }^{[8]}$ The specimens from the case presented also showed distinct koilocytotic atypia. 


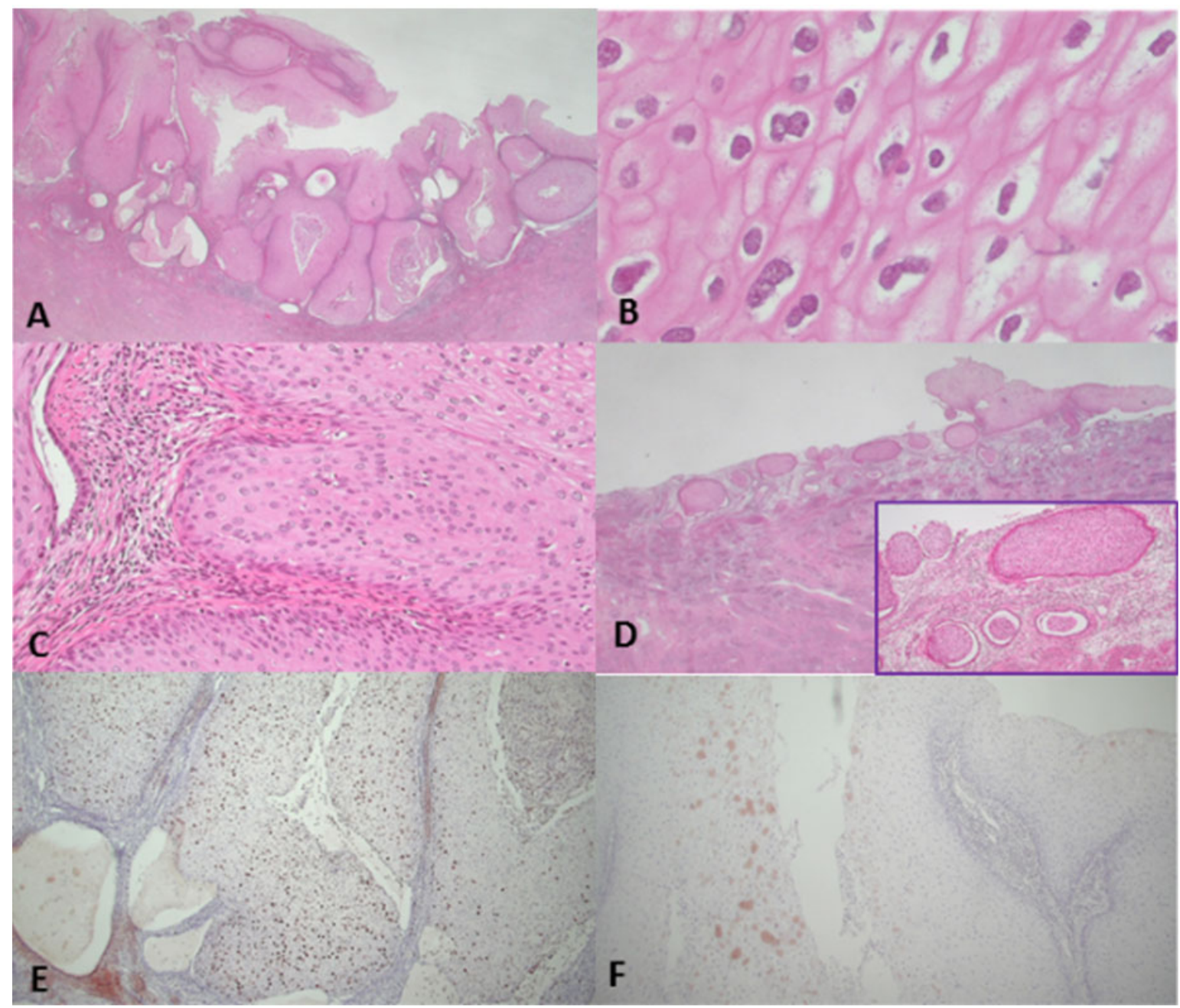

Figure 3. (A) The sections showed endophytic growing squamous nests. The top portion revealed condylomatous papillary fronds; (B) The cytomorphologic changes were typical koilocytes; (C) Foci of tongue-like projection suggestive micro-invasion; (D) The endometrium was involved via condylomatous squamous nests along the endometrial glands; (E) Ki-67 labeling index was approximately $20 \%$ in the hot spot; (F) p16 immunohistochemical staining yielded negative results for p16 expression.

A collective study of HPV in nine patients with warty carcinoma showed combined infection, for which only two cases had been related to the high-risk subtype. ${ }^{[2]}$ Our patient also showed combined infection of 6 (low risk, +++ ) and 42 (low risk, +).

Recently, Ki-67 expression of the intermediate and superficial layers has been evaluated for each possible cause of condyloma transformation: invasive SCC, cervical intraepithelial neoplasia (CIN) 2/3, CIN 1, and non-dysplasia. ${ }^{[9]}$ The result were $100 \%$ positive in SCC, $75 \%$ positive in CIN 2/3, $22 \%$ positive in CIN 1, and $11 \%$ positive in non-dysplasia. However, in the case presented, the Ki-67 expression could be seen in the intermediate and even superficial layers. The Ki-67 labeling index (LI) of surface epithelium has been reported as follows: $18.3 \%$ in CIN 1, 27.0\% in CIN 2, 41\% in CIN 3, and 48.0\% in microinvasive SCC. ${ }^{[10]}$

P16INK4a expression had been evaluated in premalignant and malignant cervical lesions. ${ }^{[3]}$ Only one-third of histologic low grade squamous intraepithelial lesions show diffuse p16 immunostaining. ${ }^{[11]}$ Performance of p16/Ki-67 immunostaining to detect HSIL was done prior to the detection of high risk types of HPV, due to its specificity. ${ }^{[12]}$

Considering p16 negativity and relatively low Ki-67 LI, this case could have been one of a carcinomatous change from condyloma acuminatum or a combined biphasic tumor.

Superficial spreading micro-invasive SCC arising from CIN with endometrial involvement has been reported in a literature review of 20 cases. ${ }^{[13]}$ In our patient micro-invasive SCC involved the endometrium along the endometrial glands. 
This phenomenon might be a reserve cell hyperplasia with HPV infection, which is similar in glandular extension of CIN. ${ }^{[14]}$ We hypothesize that the so called "top down" differentiation could possibly be squmocolumnar junction of the endometrial gland as well as the transformation zone. However, this phenomenon is not related to the FIGO staging, and vertical spread is not a concern.

Giant condyloma of the cervix is a particularly important differential diagnosis. A collective review of cervical giant condyloma has been reported with all the four cases showing verruciform architecture with viral cytopathic change, related to low risk HPV types 6, and 11. ${ }^{[15]}$ The differential features were 1) conspicuous atypia; 2) mitotic activity at the basal layers and 3) infiltrative stromal invasion.

Although no remarkable cytomorphologic atypia with p16 negativity is seen, the diagnosis of an "exclusively benign lesion" should be avoided in limited specimens. Warty carcinoma or verrucous carcinoma cannot be ruled out. In the case presented, focal micro-invasion on punch biopsy, could not be excluded. In the differential diagnoses of benign condylomatous lesions, the patient's age is very important and is associated with tumor development in young or immunosuppressed women.

Although clinical experience with these tumors is very limited, they appear to behave less aggressively than typical well differentiated squamous cell carcinoma of the cervix. Warty carcinoma of the uterine cervix has been reported within 50 cases in literature review. The largest series of 9 cases showed 54.1 years of mean age (40-77 years) and variable stage IA1 to IIA. The size of tumors ranged from $0.8 \mathrm{~cm}$ to $6 \mathrm{~cm}$. However, all nine cases revealed an excellent outcome: no evidence of disease (NED) during 0.7 to 18.2 years of follow-up periods. ${ }^{[2]}$ In this presented, the patient was well without evidence of disease three months post-operatively.

\section{CONFlicts OF INTEREST Disclosure}

The authors declare that they have no competing interests.

\section{REFERENCES}

[1] Kurman RJ, Norris HJ, Wilkinson EJ. Tumors of the cervix. In: Kurman RJ, Norris HJ, Wilkinson EJ, (Eds.) Atlas of tumor pathology. Washington, DC: AFIP; 1992. 29-36 p.

[2] Cho NH, Joo HJ, Ahn HJ, et al. Detection of human papillomavirus in warty carcinoma of the uterine cervix: comparison of immunohistochemistry, in situ hybridization and in situ polymerase chain reaction methods. Pathol Res Pract. 1998; 194(10): 713-720. https://doi.org/10.1016/S0344-0338(98)80131-3

[3] Izadi-Mood N, Asadi K, Shojaei H, et al. Potential diagnostic value of P16 expression in premalignant and malignant cervical lesions. $\mathrm{J}$ Res Med Sci. 2012; 17(5): 428-433. PMid: 23626605.

[4] Kovi J, Tillman RL, Lee SM. Malignant transformation of condyloma acuminatium. A light microscopic and ultrastructural study. Am J Clin Pathol. 1974; 61(5): 702-710. PMid: 4827053. https: //doi.org/10.1093/ajcp/61.5.702

[5] Shafeek MA, Osman MI, Hussein MA. Carcinoma of the vulva arising in condylomata acuminata. Obstet Gynecol. 1979; 54(1): 120-123. PMid: 450355. https ://doi .org/10.1097/00006250 -197907000-00027

[6] Dawson DF, Duckworth JK, Bernhardt H, et al. Giant condyloma and verrucous carcinoma of the genital area. Arch Pathol. 1965; 79: 225-231. PMid: 14246201. https ://doi.org/10.1097/LGT. Ob $013 \mathrm{e} 3181 \mathrm{c} 945 \mathrm{ed}$

[7] Dane B, Dane C, Erginbas M, et al. Verrucous carcinoma of the cervix in a case with uterine prolapse. Ann Diagn Pathol. 2009; 13(5): 344-346. PMid: 19751912. https://doi.org/10.1016/j . anndiagpath.2009.02.005

[8] Brinck U, Jakob C, Bau O, et al. Papillary squamous cell carcinoma of the uterine cervix: report of three cases and a review of its classification. Int J Gynecol Pathol. 2000; 19(3): 231-235. PMid: 10907171. https://doi.org/10.1097/00004347-200007000-00006

[9] Kanthiya K, Khunnarong J, Tangjitgamol S, et al. Expression of the p16 and Ki67 in Cervical Squamous Intraepithelial Lesions and
Cancer. Asian Pac J Cancer Prev. 2016; 17(7): 3201-3206. PMid: 27509952.

[10] Kimura M, Matsumoto T, Morizane T, et al. Histopathological study of the spreading neoplastic cells in cervical glands and surface epithelia in cervical intra-epithelial neoplasia and microinvasive squamous cell carcinoma: Ki-67 immunostaining is a useful marker for pathological diagnosis from the gland involvement site. Pathol Int. 2006; 56(8): 428-433. PMid: 16872436. https : //doi.org/10.1111/j.1440-1827.2006.01984.x

[11] Stoler M, Bergeron C, Colgan TJ, et al. Tumours of the Uterine Cervix In: Kurman RJ, Carcangiu ML, Herrington CS, Young RH (Eds.). WHO Classification of Tumours of Female Reproductive Organs. Lyon, France: IARC and WHO; 2014. 172-182 p.

[12] Wentzensen N, Schwartz L, Zuna RE, et al. Performance of p16/Ki-67 immunostaining to detect cervical cancer precursors in a colposcopy referral population. Clin Cancer Res. 2012; 18(15): 4154-4162. PMid: 22675168. https://doi.org/10.1158/1078-0432. CCR-12-0 270

[13] Tan GC, Isa MR, Ng SP, et al. Unusual form of superficial spreading microinvasive squamous cell carcinoma of uterine cervix involving the endometrium of uterus. J Obstet Gynaecol Res. 2004; 30(5): 363-367. PMid: 15327449. https://doi.org/10.1111/j.1447 $-0756.2004 .00210 . \mathrm{x}$

[14] Herfs M, Vargas SO, Yamamoto Y, et al. A novel blueprint for 'top down' differentiation defines the cervical squamocolumnar junction during development, reproductive life, and neoplasia. J Pathol. 2013; 229(3): 460-468. PMid: 23007879. https ://doi.org/10.1002/ path. 4110

[15] Parra-Herran C, Herfs M, Doria M, et al. Giant condyloma of the cervix: an uncommon entity associated with low-risk human papilloma virus infection. Am J Surg Pathol. 2013; 37(2): 300-304. PMid: 23282973. https://doi.org/10.1097/PAS.0b013e31826d26 $1 \mathrm{e}$ 